\title{
Prevalence of RhD status and clinical application of non-invasive prenatal determination of fetal $R H D$ in maternal plasma: a 5 year experience in Cyprus
}

Thessalia Papasavva ${ }^{1 *}$, Pete Martin², Tobias J. Legler ${ }^{3}$, Marios Liasides $^{4}$, George Anastasiou ${ }^{5}$, Agathoklis Christofides ${ }^{6}$, Tasos Christodoulou ${ }^{7}$, Sotos Demetriou ${ }^{8}$, Prokopis Kerimis ${ }^{9}$, Charis Kontos ${ }^{10}$, George Leontiades ${ }^{11}$, Demetris Papapetrou ${ }^{5}$, Telis Patroclos ${ }^{12}$, Marios Phylaktou ${ }^{7}$, Nikos Zottis ${ }^{13}$, Eleni Karitzie ${ }^{1}$, Eleni Pavlou' ${ }^{1}$ Petros Kountouris ${ }^{1}$, Barbera Veldhuisen ${ }^{14}$, Ellen van der Schoot ${ }^{14}$ and Marina Kleanthous ${ }^{1}$

\begin{abstract}
Background: After the discovery that cell-free fetal DNA (cffDNA) is circulating in the maternal plasma of pregnant women, non-invasive prenatal diagnosis for fetal RhD in maternal plasma in RhD negative women at risk for haemolytic disease of the newborn (HDN) was clinically established and used by many laboratories. The objectives of this study are: (a) to assess the feasibility and report our experiences of the routine implementation of fetal RHD genotyping by analysis of cffDNA extracted from maternal plasma of RhD negative women at risk of HDN, and (b) to estimate the RhD phenotype frequencies, the RHD genotype frequencies and the RhD zygosity in the Cypriot population.
\end{abstract}

Methods: cffDNA was extracted from maternal plasma of 73 RhD negative pregnant women. Real-Time MultiplexPCR was used to amplify regions of RHD gene in exons 4, 5 and 10. RhD phenotypes were determined on 445 random samples using conventional agglutination slide test.

Results: The fetus was predicted to be positive in 53 cases and negative in 18 cases. Two of cases were identified as D-variants, weak D type-1 and 11. The frequency of RhD negative homozygosity in the Cypriot population was estimated to be $7.2 \%$, while the frequencies of RHD hemizygosity and RhD positive homozygosity was calculated to be 39.2 and $53.6 \%$, respectively.

Conclusion: Fetal RHD genotyping can be accurately determined using cffDNA from maternal plasma. The implementation of the test has eliminated all use of unnecessary anti-D and reduced the total use of anti-D by $25.3 \%$ while achieving appropriate management of the RhD negative pregnancies.

Keywords: NIPD, Fetal RHD genotyping, RhD frequency, Cell-free fetal DNA

\section{Background}

The discovery that during pregnancy fetal DNA is circulating in maternal plasma and constitutes about $10 \%$ of the total plasma DNA has opened up new avenues in

\footnotetext{
*Correspondence: thesalia@cing.ac.cy

${ }^{1}$ Molecular Genetics Thalassaemia Department, The Cyprus Institute of Neurology and Genetics, 6 Internanional Airport Ave, Agios Dometios, 1683 Nicosia, Cyprus

Full list of author information is available at the end of the article
}

non-invasive prenatal diagnosis (NIPD) [1-3]. This discovery led to the development on NIPD for fetal sex and fetal RhD during pregnancy [4-7]. The development of a reliable and sensitive assay is based on its ability to discriminate fetal DNA from the coexisting background of maternal DNA by detecting differences between the two. NIPD of fetal sex for X-linked disorders by performing real-time PCR using Y chromosome specific targets was one of the first clinical applications of NIPD [4, 8]. Soon 
after, NIPD for fetal $\mathrm{RhD}$ in maternal plasma in $\mathrm{RhD}$ negative women for the identification of pregnancies at risk for haemolytic disease of the newborn was clinically established and used by many laboratories [9-12].

RHD and RHCE genes located at chromosomal position 1p34.1-1p36 encode for the antigens of the $\mathrm{Rh}$ blood group. The genes are highly homologous encompassing 10 exons, while the $R H D$ gene is flanked by two homologous DNA segments of the upstream and downstream Rhesus boxes [13, 14] (Fig. 1). In Caucasians, the $\mathrm{RhD}$ negative phenotype is usually caused by a deletion of the RHD gene that occurs by an unequal crossing-over between the Rhesus boxes leaving only a single hybrid Rhesus box [14].

The $\mathrm{RhD}$ negative phenotype is most common in Caucasians with a frequency of approximately $15 \%$, less common in Africans with $8 \%$ frequency and rare in Asians with less than $1 \%$ frequency [15]. About $66 \%$ of $\mathrm{RhD}$ negative Africans have an inactive $R H D$ gene, a pseudogene $\left(R H D^{*} \Psi\right)$ that results from a 37-bp insertion in exon 4 that introduces a stop codon, whereas about $16 \%$ have the $R H D-C E-D^{s}$ hybrid gene $[16,17]$. About $0.2-1 \%$ of Caucasians have red blood cells with a reduced expression of the D antigen (weak D) [18]. Single point mutations in $R H D$ which encoding amino acid changes leading in a reduced number of $\mathrm{D}$ antigen sites on the red blood cells, are the main cause of weak D expression [19]. The identification of weak D phenotypes and genotyping is of clinical importance in terms of transfusion.

$\mathrm{RhD}$ negative pregnant women with a hemizygous RhD positive partner, have a $50 \%$ chance of having a $\mathrm{RhD}$ negative fetus. If the fetus is $\mathrm{RhD}$ negative, there is no need for immunisation. However, if the fetus is RhD positive, the $\mathrm{RhD}$ negative woman may produce antibodies (alloimmunisation) to the fetal $\mathrm{RhD}$ antigens by silent fetomaternal haemorrhage during pregnancy, mostly during the third trimester and delivery, leading to the life threatening haemolytic disease of the fetus and newborn (HDFN) in a following pregnancy [20]. The injection of anti-D antibodies called $\mathrm{Rh}$-prophylaxis to all $\mathrm{RhD}$ negative pregnant women does prevent this disease in most cases. However, many RhD negative women carry a RhD negative fetus and, thus, receive anti-D unnecessarily, exposing them to the risks associated with administration of human blood products that have been associated with serious viral infections in the past [21].

The clinical application of the non-invasive test for fetal $\mathrm{RhD}$ typing was implemented soon after the discovery of circulating fetal DNA. NIPD of fetal RHD from maternal plasma of $\mathrm{RhD}$ negative mothers is considered a valuable
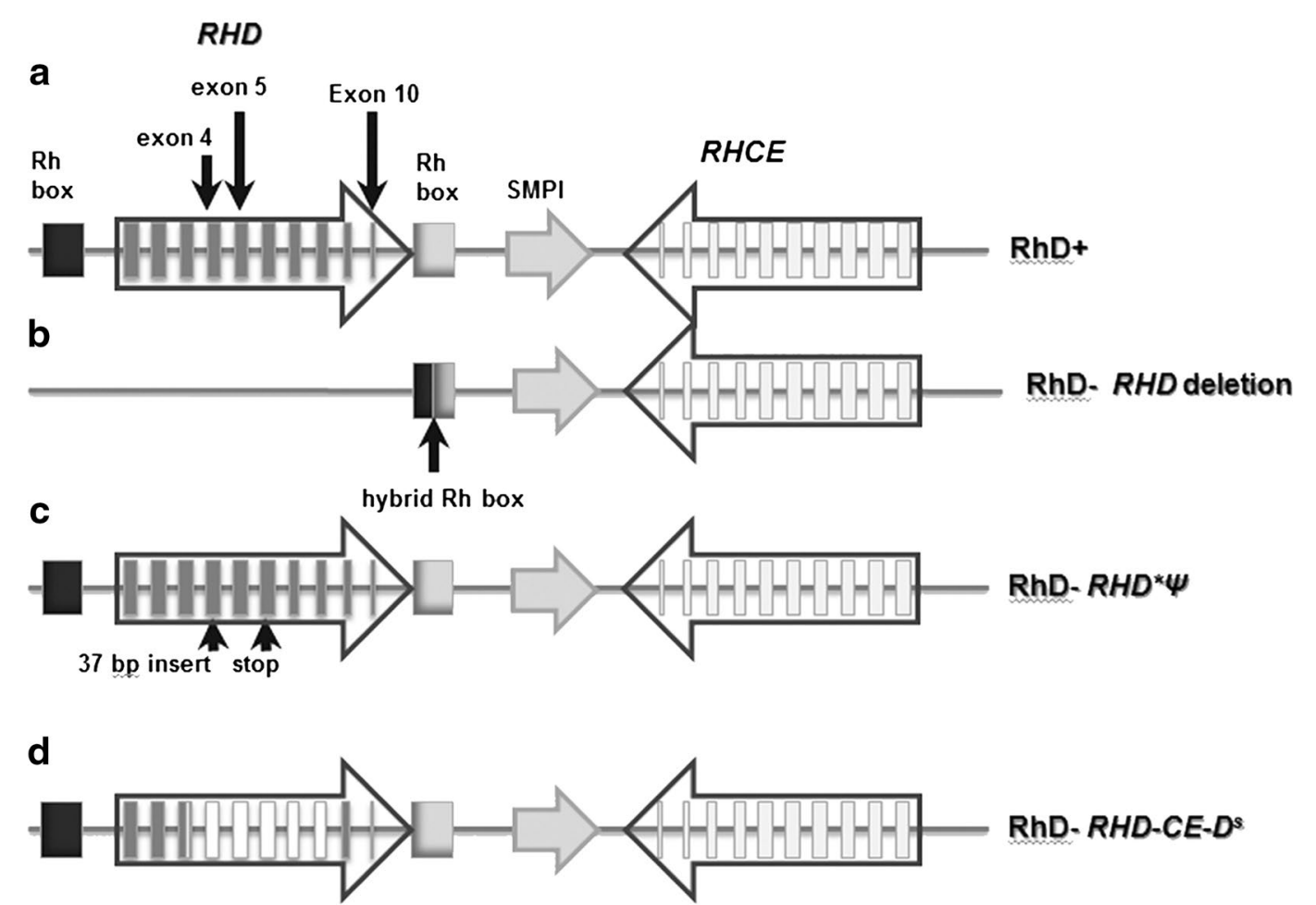

Fig. 1 Schematic structure of the RHD locus. a Normal RhD positive individuals. b RhD negative individuals. $\mathbf{c} R H D$ pseudogene. $\mathbf{d} H y b r i d ~ R H D-$ $R H C E-R H D^{s}$ gene 
tool in the identification of pregnancies at risk of HDFN and the proper management of these pregnancies, but mainly avoiding unnecessary routine $\mathrm{RhD}$ prophylaxis [22-24]. Since 2001, NIPD of fetal RHD has already been offered to pregnant women with $\mathrm{RhD}$ positive partners as a routine clinical service by the International Blood Group Reference Laboratory [25] with other European countries following [10, 26-29].

This report discusses our experiences of the routine implementation in clinical practice of fetal $R h D$ genotyping from the maternal plasma of $\mathrm{RhD}$ negative mothers in Cyprus. NIPD of fetal RHD was performed on maternal plasma on $71 \mathrm{RhD}$ negative women, referred by their obstetrician during their routine visit, targeting exons 4, 5 and 10 of the RHD gene using Real Time PCR. The child's $\mathrm{RhD}$ phenotype was confirmed serologically after birth. There is an indication of a relatively high percentage of $\mathrm{RhD}$ negative people in the Cypriot population based on the empirical observation of the gynecologists. In this work, the RhD phenotype frequency was examined and, for the first time, the $\mathrm{RhD}$ negative frequency was estimated for the Cypriot population, giving an assessment of how many couples are at risk for HDN and in turn eligible for NIPD every year.

\section{Methods}

\section{Sample collection}

Fifty maternal plasma samples from $\mathrm{RhD}$ negative pregnant women previously typed were sent by the University Medical Center Göttingen in Germany to be used for the verification of the NIPD assay already validated by the International Blood Group Reference Laboratory. Seventy-three $\mathrm{RhD}$ negative pregnant women with $\mathrm{RhD}$ positive partners at risk of HDN were referred by their obstetrician, during their routine visit, to the Cyprus Institute of Neurology and Genetics for the NIPD of fetal RHD using maternal plasma. These women were from the entire Cyprus. Nine milliliters of peripheral blood was collected in EDTA tubes after the 16th week of gestation.

Peripheral blood from 445 unrelated adults of both sexes, 222 males and 223 females, were drawn into EDTA tubes for the determination of RhD phenotype. All participants were Greek Cypriots, $\beta$-thalassaemia carriers referred to the Cyprus Institute of Neurology and Genetics between the period 2009-2010 for $\beta$-thalassaemia prenatal diagnosis purposes from the entire Cyprus. $\beta$-thalassaemia trait is not associated with $\mathrm{RhD}$ expression inheritance since the genes are located in different chromosomes.

Written informed consent was obtained from all maternal plasma samples from $\mathrm{RhD}$ negative pregnant women sent by the University Medical Center Göttingen in Germany for validation purposes. $\mathrm{RhD}$ negative pregnant women included in the study provided informed consent for the routine clinical analysis, Non-Invasive Prenatal Determination of Fetal $R H D$ in maternal plasma. The test is approved by the Board of Directors of the CING and accredited by CYS EN ISO 15189:2007. All whole blood samples were collected as part of a routine patient care after the request of the participants. The study was performed as part of our diagnostic services.

\section{DNA isolation}

For the isolation of cell-free maternal plasma from whole blood, the samples were subjected to centrifugation at low speed, $2500 \mathrm{~g}$ for $10 \mathrm{~min}$ without brake. Subsequently, maternal plasma was transferred to microcentrifuge tubes and subjected to a second centrifugation step at $16,000 \mathrm{~g}$ for $40 \mathrm{~min}$ to remove any residual cells. The maternal plasma was carefully removed and transferred into polypropylene cryogenic vials in $1 \mathrm{ml}$ aliquots and stored at $-20^{\circ} \mathrm{C}$ until further processing.

Cell-free DNA was extracted from $1 \mathrm{ml}$ of maternal plasma before DNA analysis using QIAamp Circulating Nucleic Acid Kit (Qiagen GmbH, Hilden, Germany) according to the manufacturer's instructions.

Genomic DNA was isolated from $1 \mathrm{ml}$ of peripheral blood using the Puregene Blood Core Kit C (Qiagen Sciences, Germantown, MD, USA).

\section{RhD phenotyping}

$\mathrm{RhD}$ antigen testing was performed by conventional slide test using anti-D murine monoclonal blend, Molterclone (Ortho Clinical Diagnostics, Inc., Raritan, NJ). The phenotyping test was performed on 445 randomly selected samples from the Greek Cypriot population. The genotype frequencies and zygosity were calculated, as described in the "Results" section.

\section{Fetal RhD Genotyping using real time polymerase chain reaction (PCR)}

The NIPD assay for fetal RhD implemented at our lab has been designed, validated and applied by Finning et al. at the International Blood Group Reference Laboratory in Bristol [22, 25]. Verification of the assay was performed by using fifty maternal plasma samples from $\mathrm{RhD}$ negative pregnant woman, previously typed and sent by the University Medical Center Göttingen in Germany. Real Time multiplex PCR was used to amplify the regions of RHD gene in exons 4,5 , and 10 , using 4 replicates per exon per sample (Fig. 1). The exon 4 and 5 assays are designed to amplify only $R H D$ and not $R H D^{*} \Psi$. Amplification of the $S R Y$ gene on the Y chromosome is used to confirm the presence of male fetal DNA. Amplification of the CCR5 gene, common to mother and fetus, is used to evaluate the efficiency of the DNA extraction procedure 
and to estimate the total quantity of DNA (both maternal and fetal) present in maternal plasma. Four replicates for each exon are performed in order to improve sensitivity and to verify the accuracy of the fetal RhD status. During each run, genomic DNA from $\mathrm{RhD}$ negative female as well as RhD positive male were used for negative and positive control respectively. DNA sample from a person having the $R H D$ pseudogene was also incorporated in the assay to exclude the possibility of someone carrying the pseudogene. Moreover, genomic DNA from the parents was also included for genotyping in order to confirm the phenotype.

\section{Multiplex ligation-dependent probe analysis (MLPA)}

To identify $R H D$-variants in two pregnant women, the MLPA assay was performed as previously described [30]. The MLPA fragments were analysed using a 3130 Genetic Analyzer (Applied Biosystems) and Genemarker software version 1.85 (Softgenetics, State Collage, USA). A DNA sample with a $\mathrm{RhD}$ positive phenotype and an artificial control sample consisting of a mixture of a human cell line and plasmid DNA, containing all targets within the MLPA assay were used as controls.

\section{Statistical analysis}

The data were analysed using the $\mathrm{R}$ programming language (version 3.1.2). Descriptive statistics were utilised for the analysis, while the confidence intervals (CI) were defined using the exact binomial test (function binom. test() in R). In cases where no negative effects were observed, such as the method's accuracy, the $95 \%$ CI was estimated using the rule of three [31].

\section{Results}

Determination of RHD allele frequencies in Cyprus

Random samples from 445 people from the Greek Cypriot population were tested serologically using standard haemagglutination assays to examine the phenotype and to determine the frequency of the RhD status in the Cypriot population. It was found that 32 individuals showed no agglutination with the $\mathrm{RhD}$ antigen, thus having negative $\mathrm{RhD}$ phenotype. The $32 \mathrm{RhD}$ negative identified individuals were confirmed using PCR with restriction fragment length polymorphism (PCR-RFLP) as previously described [32]. The other 413 samples demonstrated positive agglutination and hence $\mathrm{RhD}$ positive (Table 1). Therefore, $7.2 \%$ of the population in Cyprus is RhD negative (95\% CI 4.97-10.00\%). Using the HardyWeinberg equation, $p^{2}+2 p q+q^{2}=1$ with $q^{2},=0.0719$ (95\% CI 0.0497-0.1), the homozygous RHD, $p^{2}$, is calculated to be 0.536 (95\% CI 0.468-0.604). Similarly, the hemizygous RhD frequency, $2 p q$, is calculated to be 0.392 (95\% CI 0.347-0.433). These data were used to
Table 1 RhD phenotype frequencies in 445 randomly selected samples from the Greek-Cypriot population

\begin{tabular}{lrcr}
\hline RhD determination & No. & Frequencies (\%) & $\mathbf{9 5} \% \mathbf{C l}$ \\
\hline RhD positive & 413 & 92.81 & $90.00-95.03$ \\
RhD negative & 32 & 7.19 & $4.97-10.00$ \\
Total & 445 & & \\
\hline
\end{tabular}

determine the RHD zygosity, $z$, which is defined as the fraction of hemizygous $R H D$ samples over the homozygous $R H D$ plus hemizygous $R H D$ samples given by:

$$
z=\frac{\text { hemizygousRHD }}{\text { hom ozygousRHDpositive }+ \text { hemizygousRHD }}
$$

The frequency of individuals that are $R H D$ hemizygous would be $42 \%$ (95\% CI 36-48 \%) among individuals that are $\mathrm{RhD}$ positive. Based on this result, a couple with the mother being homozygous $R H D$ negative and the father hemizygous $R H D$ positive has a $21 \%$ (95 \% CI 18-24\%) reproductive chance of having a child homozygous $R H D$ negative and, therefore, not at risk of HDFN since the newborn will share the same genotype with the mother. As a result, these women take unnecessary immunoglobulin treatment.

\section{NIPD for Fetal RhD using Real Time Polymerase Chain Reaction}

The RhD status of the fetus in 71 pregnancies was determined by real-time PCR using fetal DNA derived from maternal plasma. If no $R H D$ signals are obtained for exons 4,5 and 10 , the fetus is determined to be $\mathrm{RhD}$ negative. The fetus is determined as $\mathrm{RhD}$ positive when at least two positive signals are obtained from each $R H D$ exon plus a total of three more positive signals from any exon. No grey zone results were observed. The presence of the maternal DNA was observed in all cases. Based on the above criteria, the fetus was predicted to be positive in 53 cases and negative in 18 cases (Table 2). As a result, these women did not receive any anti-D prophylaxis and, therefore, a $25.3 \%$ reduction in anti-D prophylaxis was achieved. Moreover, a better and closer monitoring was provided to the RhD positive pregnancies.

Table 2 NIPD of fetal RHD on maternal plasma of RhD negative pregnant women

\begin{tabular}{lll}
\hline $\begin{array}{l}\text { Fetal RhD } \\
\text { determination }\end{array}$ & $\begin{array}{l}\text { No.(\%) } \\
\text { of patients }\end{array}$ & $\begin{array}{l}\text { Serological confirmation } \\
\text { on the newborn's } \\
\text { phenotype }\end{array}$ \\
\hline Positive & $53(74.6)$ & 53 \\
Negative & $18(25.3)$ & 18 \\
Total & 71 & 71 \\
\hline
\end{tabular}




\section{Identification of $D$ variant cases}

During the routine fetal RhD genotyping two discrepancies were observed. In both cases, the mother, being serologically negative was referred to us for NIPD of fetal $\mathrm{RhD}$ from maternal plasma. However, upon genotyping the maternal genomic DNA sample with Real Time PCR, $R H D$ sequences were detected in the mother's sample indicating that the mother is $\mathrm{RhD}$ positive. In order to confirm this discrepancy, PCR-Restriction Enzyme Digestion was also performed on the maternal genomic DNA samples to test for RhD zygosity. Both cases were found to be hemizygous. Therefore, with the aim of investigating these serologic discrepancies in $\mathrm{RhD}$ typing, the samples were referred to Sanquin center in Amsterdam to investigate for possible RhD variants. Multiplex Ligation Probe Amplification (MLPA) was performed on both samples where it was found that sample 1 was weak D type $1 / \mathrm{d}$ Cc ee $(R H D * 01$ W.01) having the nucleotide change $809 \mathrm{~T}>\mathrm{G}$, while sample 2 was weak D type $11 / \mathrm{d}$ $C$ ce e $\left(R H D^{* 11}\right)$ with nucleotide change $885 \mathrm{G}>\mathrm{T}$. These $\mathrm{D}$ variants have a reduced expression of the $\mathrm{RhD}$ antigen that arise from single point mutations on the RHD gene encoding amino acid changes and, hence, no agglutination is performed explaining the negative serology result. Therefore, NIPD cannot be performed on these samples since $R H D$ sequences are present in the mother's genome.

\section{Confirmation of fetal RhD status}

Serological tests on the infant's red blood cells (RBCs) were performed and $\mathrm{RhD}$ type was confirmed after delivery on all samples tested after contact with the referring physician and receipt of written confirmation of the newborn's serological analysis (Table 2). When compared to postpartum serological results, an accuracy rate of $100 \%$ (95\% CI 95.3-100\%) was achieved in our prenatal prediction of fetal $\mathrm{RhD}$ status. No false negative or false positive results were obtained on the 71 samples that were cross checked.

\section{Discussion}

In this study, we have determined the RhD phenotype status of 445 random samples in an attempt to establish the frequency of the RHD negative allele in the Cypriot population. As a result, the frequency of the $\mathrm{RhD}$ negative phenotype in the Cypriot population is found to be $7.2 \%$ (95 \% CI 5-10\%), a value that is demonstrated to be different from that reported in the literature where it is stated that about $15 \%$ of Caucasians do not express the $\mathrm{RhD}$ antigen. However, it is more consistent with $8.59 \%$ frequency reported for the Greek population [33]. In non-European populations the frequency of the RhD negatives is much lower than Caucasians with Africans having $8 \%$, higher than the Cypriots, and Asians $1 \%$ [15]. It is reported that in western European populations the frequency is greater, the highest for instance of 21-36 \% in the Basque French population [34]. The determination of the frequency of $R H D$ negative alleles in Cyprus it is also important as it gives an indication, of how many couples are at risk for HDFN, a number that differs from what applies to Caucasians, and therefore in need for the prenatal determination of fetal $R H D$ with maternal plasma. The determination of the paternal $R H D$ zygosity is valuable in clinical setting as it can aid in the assessment of a couple's risk of carrying a $\mathrm{RhD}$ positive child and in turn in risk of HDFN related to anti-D. The reported frequency of $R H D$ hemizygosity would be around $56 \%$ [35], for the Caucasians, however our study demonstrated a frequency zygosity value of $42 \%$ among individuals that are $\mathrm{RhD}$ positive, in the Cypriot population, a value that is consistent with the lower $\mathrm{RhD}$ negative phenotype observed. Based on our results, fathers who are $R H D$ positive have a $21 \%$ predicted chance of a homozygous $\mathrm{RhD}$ negative fetus. Hemizygous $R H D$ males have a $50 \%$ chance of having a RhD negative offspring, in which case the pregnancy will not be at risk for HDFN.

Several studies have demonstrated the feasibility and accuracy of prenatal determination of fetal $R H D$ with maternal plasma. A number of centers worldwide have reported the introduction of the test in their clinical practice. We have also applied the non-invasive fetal $\mathrm{RhD}$ genotyping in maternal plasma in a routine diagnostic setting in our lab and we have tested 71 samples since 2009. Our results were confirmed with the serological test on the newborns red cells on all samples tested. With the implementation of this method into routine clinical practice, we have achieved $25.3 \%$ reduction in the administration of anti-D since 18 out of the $71 \mathrm{RhD}$ negative women were predicted to have a $\mathrm{RhD}$ negative fetus. The observed difference, although relatively close, between the achieved value of $25.3 \%$, and the predicted one, $21 \%$, could be related to the small number of maternal plasma samples analysed compared to the 445 samples from which the predicted value was derived. Nevertheless, the implementation of the non-invasive fetal $\mathrm{RhD}$ testing and the high accuracy rate achieved is of paramount importance as it allows targeting immunoprophylaxis only to $\mathrm{RhD}$ negative pregnant women carrying an $\mathrm{RhD}$ positive fetus. Therefore, unnecessary administration of Ig anti-D to those carrying $\mathrm{RhD}$ negative fetus is avoided. Moreover, the implementation of this test not only serves as an important tool for antenatal diagnosis of fetomaternal incompatibility but also allows for a better follow-up and management of anti-D immunised women. 
Based on our RhD phenotyping results, around 600 pregnancies per year in Cyprus are at risk for HDNF ( $\mathrm{RhD}$ negative pregnant women with $\mathrm{RhD}$ positive partners), therefore eligible for NIPD for fetal RhD. It was observed, however, that the actual implementation of the programme into routine practice was slow with an initial number of samples far below the expected number. This might be attributed to the fact that this a fairly new test and currently the cost is not covered by the national health system. Moreover, clinicians sometimes are skeptical in embracing and adopting a new approach. We anticipate that with continuous education and a possible health care system that will cover the cost, an improvement in participation of more samples will be achieved.

Two out of the 73 samples referred for NIPD were identified as $R h D$ variants, specifically weak $D$ type 1 and 11. Weak D types result from nucleotide changes that encode amino acid substitutions in the membrane or below the membrane of the RhD polypeptide [36]. These changes affect the efficiency of insertion and, in turn, the quantity of $\mathrm{RhD}$ protein in the membrane reducing the number of $\mathrm{RhD}$ antigen sites on the red blood cells [19] leading to lack of reactivity with anti-D, no agglutination is performed supporting the $\mathrm{RhD}$ negative phenotype. Although the haemagglutination assay shows a sensitivity and specificity of $99.5-100 \%$, it is accepted in the literature that weak D units may escape detection by serologic methods. However, serology is still widely used to assign $\mathrm{RhD}$ negative or $\mathrm{RhD}$ positive patient [37-39]. An estimated $0.2-1 \%$ of Caucasians carry red cells with a reduced expression of the $\mathrm{RhD}$ antigen (weak D) [18, 39] as reported in the literature. Our experience shows that about $2.7 \%$ (95\% CI $0.33-9.55 \%$ ) of $\mathrm{RhD}$ negative women carry a weak D type genotype, but a larger sample size is needed to determine whether this difference is significant. Weak D types 1-4 represent more than $90 \%$ of all weak D occurring in Europeans [40]. Appropriate assignment of $\mathrm{RhD}$ antigen status is critical since commercially available anti-D reagents react differently with $D$ variants. Patients with a weak D type 1 are treated as $\mathrm{RhD}$ positive, therefore transfused with $\mathrm{RhD}$ positive $\mathrm{RBCs}$ and as a result RhIg is not administered to pregnant women. On the other hand weak D type 11 should be treated as RhD negative, transfused with $\mathrm{RhD}$ negative RBCs and therefore RhIg is administered to pregnant women $[19,30,40]$. The above haemotherapy approach is in accordance with guidelines in Europe [40], however, in Cyprus there are no guidelines, since all weak D types are managed as $\mathrm{RhD}$ negative. The identification of weak D types and their classification will assist in the development of a more efficient guidance and management of an $\mathrm{RhD}$ negative transfusion policy in Cyprus. Therefore, a collaborative study with all the relevant health care offcials is highly recommended.

\section{Conclusions}

In this study, we have demonstrated the diagnostic accuracy of our NIPD test for identification of the fetal RhD status in maternal plasma and its importance in managing the $\mathrm{RhD}$ negative pregnancies. We have also demonstrated that the introduction of this test in clinical setting has eliminated the use of unnecessary anti-D and reduced the total use of anti-D by $25.3 \%$. Through the study, RhD variants were identified and defined. Moreover, we have estimated the RhD phenotype frequencies in the Cypriot population to be $7.2 \%$ (95\% CI 5-10\%) for RhD negative and $92.8 \%$ (95\% CI 90-95\%) for RhD positive. In addition, we have calculated the RHD genotypes in the Cypriot population to be $53.6 \%$ (95 \% CI 46.8-60.4\%) for RHD positive homozygous and $39.2 \%$ (95 \% CI 34.7$43.3 \%$ ) for RHD hemizygous. Finally, it is recommended that a systematic and targeted prevention based on fetal RhD genotyping from maternal plasma should be evaluated to define the impact and potential benefits on management, and quality of life.

\section{Abbreviations}

cffDNA: cell-free fetal DNA; HDN: haemolytic disease of the newborn; NIPD: non invasive prenatal diagnosis; HDFN: haemolytic disease of the fetus and newborn; MLPA: multiplex ligation-dependent probe analysis; PCR: polymerase chain reaction; $\mathrm{RBCs}$ : red blood cells.

\section{Authors' contributions}

TP and MK conceived, designed and applied the test in diagnostic setting. MK supervised the study and critically revised the study design and manuscript writing. TP performed the verification, performed the analysis of the diagnostic samples, acquired the data, analysed and interpreted the data and wrote the manuscript. PM designed and validated the NIPD protocol and reviewed manuscript and data analysis. TJL assisted in the verification of the protocol and reviewed manuscript and data analysis. EK performed the RhD phenotyping analysis. EP was involved in the fetal RhD genotyping. PK performed the statistical analysis. BV and EvdS performed the MLPA analysis and reviewed manuscript and data analysis. ML and GA collected and send the majority of samples for diagnosis. All of the physicians ML, GA, TC, AC, SD, PK, CK, GL, DP, TP, MP, NZ contributed in the collection of samples for diagnosis. All of the authors made substantial contribution to acquisition of data as well as they have been involved in revising the manuscript critically for important intellectual content. All authors read and approved the final manuscript.

\section{Author details}

1 Molecular Genetics Thalassaemia Department, The Cyprus Institute of Neurology and Genetics, 6 Internanional Airport Ave, Agios Dometios, 1683 Nicosia, Cyprus. ${ }^{2}$ International Blood Group Reference Laboratory, Bristol Institute for Transfusion Sciences, NHS Blood and Transport, North Bristol Park, Filton, Bristol BS34 7QG, UK. ${ }^{3}$ Department of Transfusion Medicine, University Medical Center Göttingen, Robert-Koch-Straße 40, 37075 Göttingen, Germany. ${ }^{4}$ Zoodochou Pigis Clinic, 9 Antisthenous, Kapsalos, 3086 Limassol, Cyprus. ${ }^{5}$ Mother and Child Medical Center, 9-11 Penelopis Delta Str., 1076 Nicosia, Cyprus. ${ }^{6}$ Ultrasound Department, Makarios Hospital, 6 Koritsas Str., Strovolos, Nicosia, Cyprus. ${ }^{7}$ Apollonion Private Hospital, Lefkotheou 20, Strovolos, 2054 Nicosia, Cyprus. ${ }^{8}$ European Woman's Clinic, Vyzantiou 26, Strovolos, 2064 Nicosia, Cyprus. ${ }^{9}$ Ygia Polyclinic Private Hospital, 21, Nafpliou str., 3305 Limassol, Cyprus. ${ }^{10}$ lasis Hospital, 8 Voriou Ipirou str., 8069 Paphos, Cyprus. ${ }^{11} \mathrm{G}$. Leontiades Clinic, 3 Apollonos Street, 6016 Larnaka, Cyprus. 
${ }^{12}$ Patroklou Clinic, 14 Rubens Str., 3075 Limassol, Cyprus. ${ }^{13}$ Ledra Obstetrics Gynecology Clinic, 19 Pindarou, Ayios Antonios, 1060 Nicosia, Cyprus. ${ }^{14}$ Sanquin Blood Supply, PO Box 9892, 1006 AN Amsterdam, The Netherlands.

\section{Acknowledgements}

We would like to thank Elena Kyriacou for her assistance in formatting the manuscript.

\section{Competing interests}

The authors declare that they have no competing interests.

Received: 18 August 2015 Accepted: 22 March 2016

Published online: 01 April 2016

\section{References}

1. Lo YM, Corbetta N, Chamberlain PF, Rai V, Sargent IL, Redman CW, et al. Presence of fetal DNA in maternal plasma and serum. Lancet. 1997;350(9076):485-7. doi:10.1016/S0140-6736(97)02174-0.

2. Lo YM, Tein MS, Lau TK, Haines CJ, Leung TN, Poon PM, et al. Quantitative analysis of fetal DNA in maternal plasma and serum: implications for noninvasive prenatal diagnosis. Am J Hum Genet. 1998;62(4):768-75. doi:10.1086/301800.

3. Lun FM, Chiu RW, Allen Chan KC, Yeung Leung T, Kin Lau T, Dennis Lo YM. Microfluidics digital PCR reveals a higher than expected fraction of fetal DNA in maternal plasma. Clin Chem. 2008;54(10):1664-72. doi:10.1373/ clinchem.2008.111385.

4. Costa JM, Benachi A, Gautier E, Jouannic JM, Ernault P, Dumez Y. Firsttrimester fetal sex determination in maternal serum using real-time PCR. Prenat Diagn. 2001;21(12):1070-4. doi:10.1002/pd.219.

5. Honda H, Miharu N, Ohashi Y, Samura O, Kinutani M, Hara T, et al. Fetal gender determination in early pregnancy through qualitative and quantitative analysis of fetal DNA in maternal serum. Hum Genet. 2002;110(1):75-9. doi:10.1007/s00439-001-0649-3.

6. Lo YM, Hjelm NM, Fidler C, Sargent IL, Murphy MF, Chamberlain PF, et al. Prenatal diagnosis of fetal RhD status by molecular analysis of maternal plasma. New Engl J Med. 1998;339(24):1734-8. doi:10.1056/ NEJM199812103392402.

7. Lo YM, Patel P, Wainscoat JS, Sampietro M, Gillmer MD, Fleming KA. Prenatal sex determination by DNA amplification from maternal peripheral blood. Lancet. 1989;2(8676):1363-5.

8. Finning KM, Chitty LS. Non-invasive fetal sex determination: impact on clinical practice. Semin Fetal Neonatal Med. 2008;13(2):69-75. doi:10.1016/j.siny.2007.12.007.

9. Daniels G, Finning K, Martin P, Summers J. Fetal RhD genotyping: a more efficient use of anti-D immunoglobulin. Transfus Clin Biol. 2007;14(6):56871. doi:10.1016/j.tracli.2008.03.007.

10. Rouillac-Le Sciellour C, Serazin V, Brossard Y, Oudin O, Van Le Kim C, Colin $Y$, et al. Noninvasive fetal RHD genotyping from maternal plasma. Use of a new developed Free DNA Fetal Kit RhD. Transfus Clin Biol. 2007;14(6):5727. doi:10.1016/j.tracli.2008.01.003.

11. Daniels G, Finning K, Martin P, Massey E. Noninvasive prenatal diagnosis of fetal blood group phenotypes: current practice and future prospects. Prenat Diagn. 2009;29(2):101-7. doi:10.1002/pd.2172.

12. Bombard AT, Akolekar R, Farkas DH, VanAgtmael AL, Aquino F, Oeth $P$, et al. Fetal RHD genotype detection from circulating cell-free fetal DNA in maternal plasma in non-sensitized RhD negative women. Prenat Diagn. 2011;31(8):802-8. doi:10.1002/pd.2770.

13. Wagner FF, Moulds JM, Flegel WA. Genetic mechanisms of Rhesus box variation. Transfusion. 2005;45(3):338-44. doi:10.1111/j.1537-2995.2005.04339.x.

14. Wagner FF, Flegel WA. RHD gene deletion occurred in the Rhesus box. Blood. 2000;95(12):3662-8.

15. Dean L. The Rh blood group, Chapter 7: Blood Groups and Red Cell Antigens [Internet]. Bethesda: National Center for Biotechnology Information (US); 2005.

16. Rodrigues A, Rios M, Pellegrino J Jr, Costa FF, Castilho L. Presence of the $\mathrm{RHD}$ pseudogene and the hybrid RHD-CE-D(s) gene in Brazilians with the D-negative phenotype. Braz J Med Biol Res. 2002;35(7):767-73.
17. Singleton BK, Green CA, Avent ND, Martin PG, Smart E, Daka A, et al. The presence of an RHD pseudogene containing a 37 base pair duplication and a nonsense mutation in africans with the Rh D-negative blood group phenotype. Blood. 2000;95(1):12-8.

18. Wagner FF, Gassner C, Muller TH, Schonitzer D, Schunter F, Flegel WA. Molecular basis of weak D phenotypes. Blood. 1999;93(1):385-93.

19. Rizzo C, Castiglia L, Arena E, Gangi S, Mazzola G, Caruso C, et al. Weak D and partial D: our experience in daily activity. Blood Transfus. 2012;10(2):235-6. doi:10.2450/2012.0060-11.

20. Wright CF, Burton $\mathrm{H}$. The use of cell-free fetal nucleic acids in maternal blood for non-invasive prenatal diagnosis. Hum Reprod Update. 2009;15(1):139-51. doi:10.1093/humupd/dmn047.

21. Smith DB, Lawlor E, Power J, O'Riordan J, McAllister J, Lycett C, et al. A second outbreak of hepatitis $C$ virus infection from anti-D immunoglobulin in Ireland. Vox Sang. 1999;76(3):175-80 (31045)

22. Finning K, Martin P, Daniels G. A clinical service in the UK to predict fetal Rh (Rhesus) D blood group using free fetal DNA in maternal plasma. Ann N Y Acad Sci. 1022;2004(1022):119-23. doi:10.1196/ annals.1318.019/1/119.

23. Legler TJ, Muller SP, Haverkamp A, Grill S, Hahn S. Prenatal RhD testing: a review of studies published from 2006 to 2008. Transfus Med Hemother. 2009;36(3):189-98. doi:10.1159/000216580.

24. Muller SP, Bartels I, Stein W, Emons G, Gutensohn K, Kohler M, et al. The determination of the fetal $D$ status from maternal plasma for decision making on Rh prophylaxis is feasible. Transfusion. 2008;48(11):2292-301. doi:10.1111/j.1537-2995.2008.01843.x.

25. Finning KM, Martin PG, Soothill PW, Avent ND. Prediction of fetal D status from maternal plasma: introduction of a new noninvasive fetal RHD genotyping service. Transfusion. 2002;42(8):1079-85.

26. Minon JM, Gerard C, Senterre JM, Schaaps JP, Foidart JM. Routine fetal RHD genotyping with maternal plasma: a fouryear experience in Belgium. Transfusion. 2008;48(2):373-81. doi:10.1111/j.1537-2995.2007.01533.x.

27. Rouillac-Le Sciellour C, Puillandre P, Gillot R, Baulard C, Metral S, Van Le Kim C, et al. Large-scale pre-diagnosis study of fetal RHD genotyping by PCR on plasma DNA from RhD-negative pregnant women. Mol Diagn. 2004;8(1):23-31.

28. Chitty LS, Finning K, Wade A, Soothill P, Martin B, Oxenford K, et al. Diagnostic accuracy of routine antenatal determination of fetal RHD status across gestation: population based cohort study. BMJ. 2014;349:95243. doi:10.1136/bmj.g5243.

29. Clausen FB, Christiansen M, Steffensen R, Jorgensen S, Nielsen C, Jakobsen MA, et al. Report of the first nationally implemented clinical routine screening for fetal RHD in D-pregnant women to ascertain the requirement for antenatal $\mathrm{RhD}$ prophylaxis. Transfusion. 2012;52(4):752-8. doi:10.1111/j.1537-2995.2011.03362.x.

30. Haer-Wigman L, Veldhuisen B, Jonkers R, Loden M, Madgett TE, Avent $\mathrm{ND}$, et al. RHD and RHCE variant and zygosity genotyping via multiplex ligation-dependent probe amplification. Transfusion. 2013;53(7):1559-74. doi:10.1111/j.1537-2995.2012.03919.x.

31. Hanley JA, Lippman-Hand A. If nothing goes wrong, is everything all right?: interpreting zero numerators. JAMA. 1983;249(13):1743-5.

32. McGann PT, Despotovic JM, Howard TA, Ware RE. A novel laboratory technique demonstrating the influences of RHD zygosity and the RhCcEe phenotype on erythrocyte D antigen expression. Am J Hematol. 2012;87(3):266-71. doi:10.1002/ajh.22254.

33. Lialiaris T, Digkas E, Kareli D, Pouliliou S, Asimakopoulos B, Pagonopoulou $\mathrm{O}$, et al. Distribution of $\mathrm{ABO}$ and Rh blood groups in Greece: an update. Int J Immunogenet. 2011;38(1):1-5. doi:10.1111/j.1744-313X.2010.00958.x.

34. Touinssi M, Chiaroni J, Degioanni A, De Micco P, Dutour O, Bauduer F. Distribution of rhesus blood group system in the French basques: a reappraisal using the allele-specific primers PCR method. Hum Hered. 2004;58(2):69-72. doi:10.1159/000083027.

35. Avent ND, Reid ME. The Rh blood group system: a review. Blood. 2000;95(2):375-87.

36. Silvy M, Chapel-Fernandes S, Callebaut I, Beley S, Durousseau C, Simon S, et al. Characterization of novel RHD alleles: relationship between phenotype, genotype, and trimeric architecture. Transfusion. 2012;52(9):2020-9. doi:10.1111/j.1537-2995.2011.03544.x. 
37. Noizat-Pirenne F, Verdier M, Lejealle A, Mercadier A, Bonin P, PeltierPujol F, et al. Weak D phenotypes and transfusion safety: where do we stand in daily practice? Transfusion. 2007;47(9):1616-20. doi:10.1111/j.1537-2995.2007.01332.x.

38. Silvy M, Simon S, Gouvitsos J, Di Cristofaro J, Ferrera V, Chiaroni J, et al. Weak D and DEL alleles detected by routine SNaPshot genotyping: identification of four novel RHD alleles. Transfusion. 2011;51(2):401-11. doi:10.1111/j.1537-2995.2010.02830.x.
39. Wagner FF, Frohmajer A, Ladewig B, Eicher NI, Lonicer CB, Muller TH, et al. Weak D alleles express distinct phenotypes. Blood. 2000;95(8):2699-708.

40. Flegel WA. How I manage donors and patients with a weak D phenotype. Curr Opin Hematol. 2006;13(6):476-83. doi:10.1097/01. moh.0000245694.70135.c3.
Submit your next manuscript to BioMed Central and we will help you at every step:

- We accept pre-submission inquiries

- Our selector tool helps you to find the most relevant journal

- We provide round the clock customer support

- Convenient online submission

- Thorough peer review

- Inclusion in PubMed and all major indexing services

- Maximum visibility for your research

Submit your manuscript at www.biomedcentral.com/submit
(OioMed Central 